This is the version of the article accepted for publication in Environmental Science and Technology published by ACS Publications https://doi.org/10.1021/acs.est.9b00103

Accepted version downloaded from SOAS Research Online: https://eprints.soas.ac.uk/31026/

Forthcoming in Environment Science \& Technology

\title{
Impacts of Urban Expansion on Terrestrial Carbon Storage in China
}

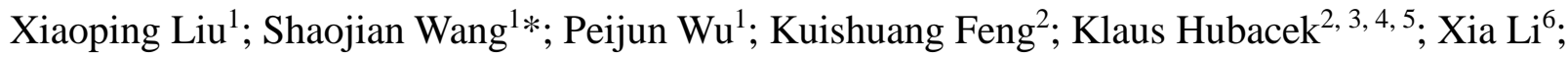
Laixiang Sun ${ }^{2,5,7 *}$

${ }^{1}$ Guangdong Provincial Key Laboratory of Urbanization and Geo-simulation, School of Geography and Planning, Sun Yat-sen University, Guangzhou 510275, China

${ }^{2}$ Department of Geographical Sciences, University of Maryland, 2181 Samuel J. LeFrak Hall, 7251

Preinkert Drive, College Park, MD 20742, USA

${ }^{3}$ Center for Energy and Environmental Sciences (IVEM), Energy and Sustainability Research Institute Groningen (ESRIG), University of Groningen, Groningen, 9747 AG, Netherlands

${ }^{4}$ Department of Environmental Studies, Masaryk University, Brno, Czech Republic.

${ }^{5}$ International Institute for Applied Systems Analysis, Schlossplatz 1 - A-2361 Laxenburg, Austria

${ }^{6}$ School of Geographic Sciences, Key Laboratory of Geographic Information Science (Ministry of Education), East China Normal University, 500 Dongchuan Road, Shanghai 200241, PR China

7 School of Finance \& Management, SOAS University of London, London, WC1H 0XG, UK.

*Correspondence: wangshj8@mail.sysu.edu.cn (S.W.); LSun123@umd.edu (L.S.)

Abstract: Urban expansion is one of the main factors driving terrestrial carbon storage (TCS) 
changes. Accurate accounting of TCS and rigorous quantification of its changes caused by historical urban expansion may help us to better predict its changes in the future. This study focuses on the carbon impacts of urbanization in China where the share of the urban population has increased from 18\% in 1978 to 59\% in 2017 and the growing will continue in the coming decades. Our results show that China's TCS decreased at an accelerating pace over the past three decades with an average reduction of $0.72 \mathrm{TgC} / \mathrm{y}$ in 1980-1990 and 8.72TgC/y in 2000-2010, mostly due to conversion from cropland and woodland to urban land. Through simulating urban expansion under four scenarios from 2010 to 2050, we found a potential increasing trend in land conversion from woodland to urban land. This conversion trend would result in carbon storage loss at an average rate of 9.31TgC/y 12.94TgC/y in 2010-2050. The increasing trend in both land conversion and carbon storage loss is especially visible in the population centers of the Yangtze River Delta and the Pearl River Delta. Considering that the indirect emission effects of urbanization, such as farmland displacement, population migration, and land degradation, may be much larger, the overall emission impact of forthcoming urban expansion in China would increase the uncertainty of the nation's carbon emissions and potentially undermine China's targets as committed in the Paris Climate Agreement.

Keywords: Urban expansion; Terrestrial carbon storage; Development scenarios; InVEST model; FLUS model; Urban agglomerations

\section{1 | INTRODUCTION}

Terrestrial ecosystems influence the climate system through carbon exchanges between these ecosystems and the atmosphere. ${ }^{1-3}$ By capturing and storing carbon from the atmosphere, the carbon dioxide $\left(\mathrm{CO}_{2}\right)$ concentration of the atmosphere decreases and the carbon storage of terrestrial ecosystems increases. On the other hand, carbon storage loss in terrestrial ecosystems leads to increased $\mathrm{CO}_{2}$ concentration in the atmosphere and thus contributing to global warming. $^{2-9}$ Carbon storage dynamics are affected by wildfires, timber harvesting, land 
management and land cover/land use change. 7, 9, 10 Among these factors, land use conversion caused by human activities has been recognized as a leading driver for loss of global terrestrial carbon storage. ${ }^{11-14}$ As a result, the impact of land-use changes on carbon storage and balance has been a focus of global change research in recent decades. ${ }^{15-18}$

With ongoing rapid urbanization, the share of global population living in towns and cities was projected to reach $70 \%$ by $2050 .{ }^{19}$ Under this trend, urbanization will be a major contributor to global land use change. ${ }^{19-22}$ With urban areas expanding, cropland and woodland are shrinking and become increasingly fragmentized, ${ }^{23-24}$ causing negative impacts on ecosystems. ${ }^{25-26}$ Therefore, simulating the impact of urban expansion on terrestrial carbon storage is of great significance for climate regulation and ecological balance.

China has experienced fast urbanization and economic development since the reform and opening up, with the share of urban population soaring from $17.9 \%$ in 1978 to $58.52 \%$ in 2017. ${ }^{27-29}$ Owing to its vast territory extending across various climate zones and diverse ecosystems, China is a critical region for global carbon storage research. ${ }^{2}{ }^{30}$ Moreover, in its commitment to the Paris Climate Agreement, China targeted at reaching peak carbon emissions by around 2030 and then achieving declines thereafter. China also committed to increasing the share of non-fossil fuels, increasing the volume of forest stocks, and reducing carbon emissions per unit of GDP. ${ }^{31}$ Therefore, research on China's terrestrial carbon storages and the effects of land-use change in general and urbanization in particular is very important for China's carbon mitigation efforts.

The $13^{\text {th }}$ Five-Year Plan (2016-2020) of China mandated an acceleration in urbanization and prioritized the rapid expansion of nineteen urban agglomerations, including megacities and population centers such as Beijing-Tianjin-Hebei, the Yangtze River Delta (YRD), and the Pearl River Delta (PRD). These urban agglomerations are planned to be closely interconnected by means of highly developed transportation and information networks to form a relatively complete urban complex. ${ }^{32-34}$ Such large-scale, rapid and ongoing urbanization makes China a unique case for a systematic assessment of the impact of urban expansion on terrestrial carbon 
storage change. In addition, the availability of detailed land-use maps derived from remote-sensing images in combination with the latest advances in carbon storage modeling and the cellular-automata based land-use modeling provides us a rare opportunity to carry out such a systematic assessment.

A few studies have been conducted to assess carbon storage change in specific regions of China. ${ }^{9,14}$ However, none of them covered the whole nation or estimated the potential impacts of future urban expansion scenarios. Given the fact that Chinese regions are diverse in terms of the industrial division of labor and development stages as well as in the size of urban areas and regional population, it is essential to provide a full picture of urban expansion and its impacts on carbon storage. Moreover, the simple classification of land use types in official data limits the accuracy of carbon storage estimation. In the current study, we carry out an improved estimation of carbon storage by taking the variation of climatic zones into consideration, which may exert significant impact on the capacity of carbon storage. ${ }^{35}$ We then provide projections of carbon storage change caused by China's urbanization under four scenarios from 2010 to 2050, at the national level and also specifically for the growing agglomerations of Beijing-Tianjin-Hebei, the YRD and the PRD. The estimation of carbon storage during 1980-2010 is based on the Integrated Valuation of Ecosystem Services and Tradeoffs (InVEST) model and the projections are carried out by coupling the Future Land Use Simulation model (FLUS model in short) developed by Liu et al. ${ }^{36}$ and the InVEST model.

\section{2 | MATERIALS AND METHODS}

\section{1 | Methods}

\subsection{1 | Overview}

In this study, we coupled the Future Land Use simulation (FLUS) model and the Integrated Valuation of Ecosystem Services and Tradeoffs (InVEST) model to simulate the impacts of urban expansion on terrestrial carbon storage. First, we calculated the carbon densities of different land cover types for five climate zones. Next, the InVEST model was used to examine 
the carbon storage changes caused by urban expansion from 1980 to 2010 both across the whole country and in the three urban agglomerations, and analyzed the share of carbon storage loss caused by conversion of cropland, woodland and grassland to new urban land. Then, we simulated the spatial distribution of future urban land under four scenarios in 2050 with FLUS model, estimating and analyzing its impacts on carbon storage variations from 2010 to 2050 in the same way as in the last step. Finally, we conducted a comparison between historical and future carbon storage changes, with the intention to highlight the hot spots with serious carbon storage loss and to identify the least environmentally damaging scenario for urban expansion.

\subsubsection{Urban expansion simulation}

Cellular Automata (CA) are widely used for modeling spatial-temporal discrete dynamical systems and have a strong capacity in spatial dynamic modeling and complex computing. Using a simple local conversion rule, CA model can generate a global complex urban development simulation. For performing well on an elaborate spatial-temporal scale, CA model and its

improved models have been extensively applied in urban simulation. ${ }^{37-39}$ A future land use simulation model, called FLUS for short, was presented recently (available for free download at http://www.geosimulation.cn/FLUS.html). ${ }^{36,40-41}$ The FLUS model is based on CA theory and has made significant improvement on the basis of traditional CA model.

The FLUS model is divided into two parts: Artificial neural network-based Probability-of-occurrence Estimation (ANNs) and Self Adaptive Inertia and Competition Mechanism CA. The ANNs model is built to estimate the probability of the conversion from non-urban land to urban land in a specific grid cell. And it has been proved that the ANNs are more effective to map nonlinear relationship, which is highly suitable for modeling the urban expansion at a large scale. ${ }^{42}$ The spatial variables, e.g., distance to the center of the provincial capital, to the center of the jurisdictive city and county town, and to rivers, provincial roads, national roads, railways and expressways, are set as the input layer. After the processing of the hidden layer, the spatial map of transition probability, i.e., the output layer, is derived. The 
self-adaptive inertia and competition mechanism is based on the binary image of urban land and non-urban land as the initial input data, and the number of grid cells of urban land and non-urban land in the target needs to be preset. To a certain extent, the target of conversion from non-urban to urban land will affect the simulation results. Therefore, in this study, a top-down system dynamic (SD) model is adopted to determine the reasonable quantity target according to the actual situation in the study area. The cost of conversion from different land use types to urban land is determined based on historical land use data, and we need to set limits on the conversion from different land use types to urban land based on empirical data and current policy. In addition to the spatial map of transition probability derived from the first part, the future urban land use dynamics can be derived.

Before simulating the urban land dynamics, the demands for urban land use should be estimated under four scenarios which cover a sufficiently broad range of socioeconomic development scenarios for China and couple both human-related and climate change factors. These scenarios refer to the baseline development scenario (BDS), fast development scenario (FDS), slow development scenario (SDS) and harmonious development scenario (HDS), designed in line with the IPCC assessment reports. ${ }^{43}$ BDS assumes that social, economic, and technological trends do not shift markedly from historical patterns (China in SSP2-RCP4.5 in the IPCC's Phase 6 of the Coupled Model Intercomparison Project CMIP6). ${ }^{44,45}$ In FDS, the economy and population are growing rapidly, and science and technology are developing rapidly (China in SSP5-RCP6.0). In contrast, SDS assumes that GDP growth rate, population growth rate and technological innovation achievements are considered to be at the lowest level (China in SSP1-RCP2.6). In HDS, stable population growth and modest development-oriented economic growth are considered, assuming that the proportion of technology investment has more investment in agricultural productivity (China in SSP3-RCP4.5).

Many previous studies proved that the overall simulation results derived by these improved CA models were stable, though the operation process of each simulation was not exactly the same. ${ }^{46}$ To evaluate the ANN model performance in terms of fitting the individual land use 
probability-of-occurrence, the Receiver Operating Characteristic (ROC) curve and the Area Under ROC Curve (AUC) values are typically employed. ${ }^{47}$ The ROC curve is plotted with the true positive rate (known as the sensitivity in machine learning) against the false positive rate (estimated with " 1 - specificity”), where the former is on y-axis and the latter is on the x-axis. A larger area under the ROC curve (AUC value) indicates a better model fitting performance. A completely random model yields an AUC value of 0.5 , and a model with perfect fit yields an AUC value of 1.0 .

\subsection{3 | Carbon storage assessment}

Many studies have been conducted to estimate the relationship between urban expansion and carbon storage change, with field surveys, remote sensing and model assessment. Field surveys, including outdoor sampling and measurement with professional instruments, is very time-consuming and resource intensive, and thus is commonly used in single ecosystems such as grassland ${ }^{48}$ and carbon pool like soil carbon ${ }^{49}$. Despite of its limitations, field survey data are fundamentally important for parameters calibration in model assessment and for verification of remote-sensing results. ${ }^{11,50}$ Based on remote sensing images, NDVI (Normalized Difference Vegetation Index) and LAI (Leaf Area Index) can be derived and utilized for carbon storage estimation of vegetation. ${ }^{10,51}$ Last but not least, many models have been developed and improved to assess terrestrial carbon storage, of which biogeochemical models have been widely applied for taking biological processes into consideration. Characterized by requiring a large number of calibrated parameters and by complex operational processes, the biogeochemical models make it less flexible to predict the impact of urban expansion on carbon storage. In contrast, the Carbon Storage and Sequestration module of InVEST model only uses maps of land use types and carbon densities for four carbon pools (aboveground biomass, belowground biomass, soil and dead organic matter) in the measurement of terrestrial carbon storage; and moreover, recent studies have shown that InVEST has the advantage of estimating the impact of urban expansion on carbon storage in a much more straightforward way and producing reliable results. ${ }^{7,8,9,52}$ For 
example, He et al. employed InVEST to simulate the spatial distribution of future urban land in Beijing, and assessed the changes of terrestrial carbon storage caused by urbanization from 1990 to $2030 .^{9}$ An obvious limitation in He et al. ${ }^{9}$ was that the carbon densities of urban land uses were assumed as being zero, thus being unable to take consideration of the role that urban land can play for carbon storage and for urban ecosystems and services. ${ }^{21,53,54}$ In this research we provide a more detailed classification of land use types and acquire carbon densities for each land use type. As a consequence, we are able to improve the precision of estimation for Beijing, in addition to our nationwide assessment.

InVEST model is developed by the Natural Capital Project, characterized by processing multiple objectives with much less demand for input data. The carbon storage component of InVEST is based on differences of carbon densities between land use types, and users just need to input land use maps and the corresponding tables of carbon densities of the land use types according to their own research purposes. As mentioned before, carbon pools are divided into aboveground biomass, belowground biomass, soil, dead organic matter. While the terrestrial carbon storage inventory has been assessed in the existing literature based on vegetation biomass (aboveground biomass) and soil organic carbon ${ }^{55}$, we use the carbon storage InVEST model to measure the change of aboveground biomass and soil organic carbon storage in each grid cell due to urban expansion (Supporting Information Figure S1). First, the combination of the more detailed carbon density table, which we acquired for different types of natural vegetation and soil, with the spatial maps of natural vegetation and soil generates the spatial maps of carbon densities of vegetation biomass and soil organic carbon, respectively (Supporting Information Figures S2 and S3). Second, the land use map in 1980 is overlaid with the climatic zoning map to produce the climatic zoning-land use spatial distribution map. Third, the tables of carbon densities of vegetation biomass and soil organic carbon in different land use types and climatic zones are derived with zonal statistics. Fourth, the tables of carbon densities obtained from step three and the land use maps in the base year and focal assessment year are the input to the carbon storage InVEST model. 
The carbon storage InVEST model makes an assumption that the carbon density of certain land use type is a constant, and the aging period of conversion from other land use types to urban land is not take into consideration. To improve spatial accuracy under this constraint, it is necessary to more detailed classification of land-use types based on best available climate and ecological data. For this purpose, we incorporate climatic zoning into the land-use classification and calibrate carbon densities for each class of the combined land use type and climatic zone.

In more detail, Köppen-Geiger climate classification is generated based on the spatial distribution of natural vegetation. A further classification of the land use types is done by overlaying Köppen-Geiger climatic zoning map. The average soil organic carbon densities in climatic zone $i$ and land use type $j$ is calculated using Eq. (2):

$$
D_{s_{i, j}}=\sum_{k=1}^{m}\left(n_{i j k} D_{s_{i j k}}\right) / N_{i j}
$$

where $D_{s_{i, j}}$ is the average soil organic carbon densities in climatic zone $i$ and land use type $j$; $n_{i j k}$ is the amount of cell in climatic zone $i$, land use type $j$ and soil type $k ; D_{S_{i j k}}$ is the soil organic carbon densities in climatic zone $i$, land use type $j$ and soil type $k ; N_{i j}$ is the amount of cell in climatic zone $i$ and land use type $j$. The same procedure is applied to measure the vegetation carbon densities in climatic zone $i$ and land use type $j$ :

$$
D_{v_{i, j}}=\sum_{k=1}^{m}\left(n_{i j k} D_{v_{i j k}}\right) / N_{i j}
$$

\section{2 | Study area and data}

Our study covers the whole of China and also zooms into three major urban agglomerations of Beijing-Tianjin-Hebei, the YRD, and the PRD (Supporting Information Fig. S4). Data used to simulate the urban expansion and evaluate the accuracy of the simulation include: (1) two land use maps of China in 1980 and 2010, which were provided by Data Center for Resources and Environmental Sciences, Chinese Academy of Sciences (http://www.resdc.cn); (2) spatial data including distance to the center of the provincial capital, to the center of the jurisdictive city and county town, and to rivers, provincial roads, national roads, railways and expressways, which 
were acquired from relevant urban planning departments.

Data used to estimate terrestrial carbon storage include: a municipal administrative zoning map, four land use maps of China in 1980, 1990, 2000 and 2010, a table of biomass carbon densities of different types of natural vegetation in China, a table of organic soil carbon densities of different types of soil in China, a climatic zoning map and two spatial distribution maps of natural vegetation and soil in China. The Chinese municipal administrative zoning map was downloaded from National Fundamental Geographic Information System website (http://ngcc.sbsm.gov.cn/). The land use maps of China in 1980, 1990, 2000 and 2010 were provided by Data Center for Resources and Environmental Sciences, Chinese Academy of Sciences (http://www.resdc.cn). The original classification of land use types includes 7 first-level types, 26 second-level types. In this study, we intend to assess the carbon storage in terrestrial ecosystem, so water body is excluded. Based on the land use types after reclassification (Supporting Information Table S1), we calculate the carbon storage inventories with the second level land use types and analyze the results using the first level land use types. The tables of above carbon densities are acquired from relevant literatures. ${ }^{56-58}$ Köppen-Geiger climate classification is adopted in this research, which includes tropical climates, arid and semiarid climates, temperate climates, continental climates and polar climates in the first level, and is downloaded from the Internet (http://koeppen-geiger.vu-wien.ac.at/). The spatial distribution maps of natural vegetation and soil were separately made in 1980 by Big Data Center of Science in Cold and Arid Regions and Institute of Soil Science, Chinese Academy of Sciences (http://westdc.westgis.ac.cn; http://www.issas.ac.cn/).

\section{3 | Results and Discussion}

\subsection{Carbon densities of different land use types}

Soil organic carbon (SOC) densities are much higher than aboveground carbon densities (SI Table S2). In addition, aboveground carbon densities are much more sensitive to the change of climatic zones. Tropical zones have the highest aboveground carbon densities whereas the 
continental zones have the highest SOC densities. A comparison across land use types indicates that woodland has the highest composite carbon densities of woodland, followed by cropland, and grassland, then by waterbody and unused land. In terms of geographical distribution, regions with the highest SOC densities are mainly distributed in the northeastern and central China. Southern China hosts the highest aboveground carbon densities for six of the seven land use types, with the exception of the woodland. Northwestern China hosts the lowest aboveground carbon and SOC densities of all seven land use types.

\section{2 | Carbon storage loss caused by urban expansion from 1980 to 2010}

The national carbon storage loss caused by urban expansion had increased at an ever-accelerating pace over the past 30 years. During the periods of 1980-1990, 1990-2000 and 2000-2010, the carbon storage decreased by $7.24 \mathrm{TgC}, 14.59 \mathrm{TgC}$ and $87.20 \mathrm{TgC}$, respectively $\left(1 \mathrm{TgC}=10^{6} \mathrm{tC}\right.$; “carbon storage loss" in the following sections refer to "carbon storage loss caused by urban expansion”; SI Fig. S5). The average annual carbon storage loss from 2000 to 2010 was 12.05 times the corresponding figure from 1980 to 1990. Among the sources of the new urban land, the carbon storage loss caused by conversion from cropland, woodland and grassland to urban land accounted for more than $90 \%$ of total carbon storage loss (Fig. 1). Carbon storage loss caused by the conversion from cropland to urban land continuously made up the largest percentage of the total carbon storage loss during the past 30 years. Over the first ten years, carbon storage loss caused by the conversion from cropland to urban land was up to 5.18TgC, accounting for $71.58 \%$ of the carbon storage loss. This share was shrinking to $51.59 \%$ during the period of $2000-2010$. In contrast to cropland, carbon storage loss caused by conversion from woodland and grassland to urban land accounted for an increasing share, and the growth was especially obvious for the former. During the periods of 1980-1990, 1990-2000, 2000-2010, the carbon storage loss caused by conversion from woodland to urban land amounted to 0.81TgC, 2.60TgC and 24.56TgC, accounting for $11.20 \%, 17.79 \%$ and $28.16 \%$ of the total losses in the corresponding periods, respectively. If the current trends persisted, the conversion from woodland to urban land would 
become the main cause of carbon storage loss in China in the future.

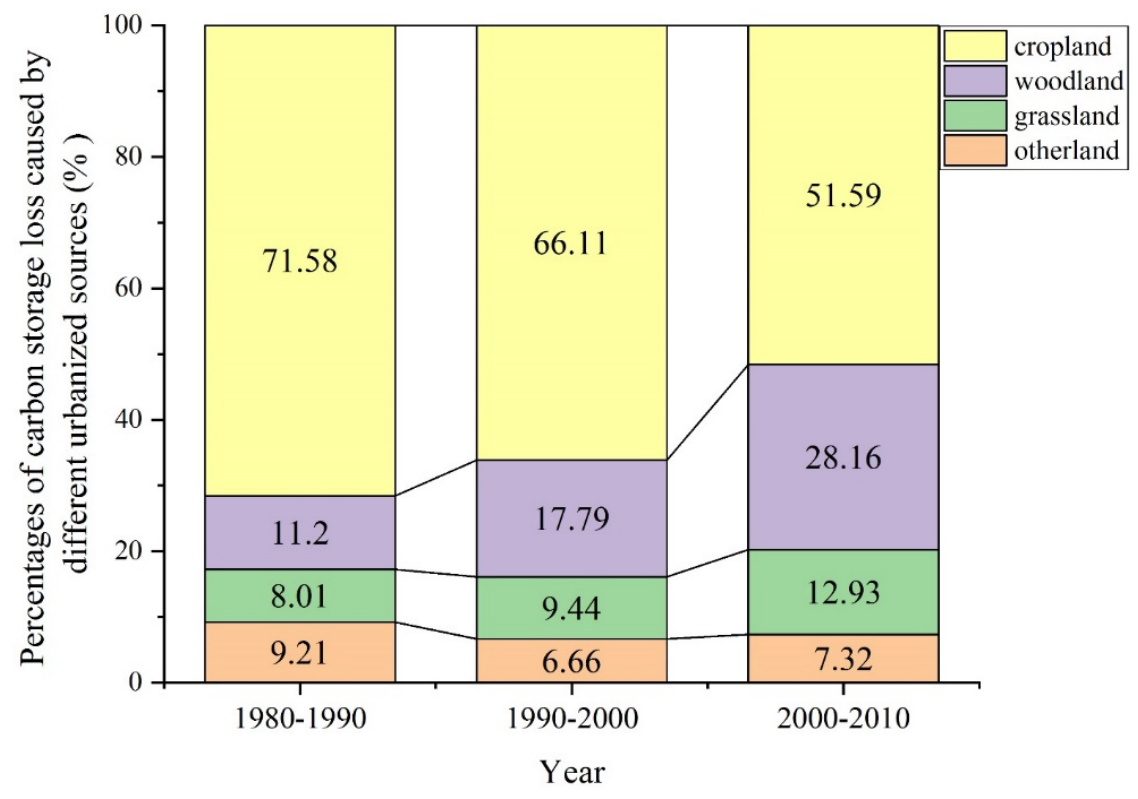

Fig. 1 The proportions of carbon storage loss by major land sources of urbanization in China. Percentages represent the shares of the carbon storage loss caused by the conversion from cropland, woodland and grassland to new urban land in the total carbon storage loss caused by the above-mentioned conversion. Carbon storage loss caused by the conversion from unused land and reclaimed land to new urban land are ignored for the small percentage they account for (add up to less than 10\%).

Among the three urban agglomerations, the maximum carbon storage reduction occurred in Beijing-Tianjin-Hebei, followed by the YRD and then the PRD over the past 30 years (Supporting Information Table S3). Carbon storage in Beijing-Tianjin-Hebei decreased by 12.03TgC between 1980 and 2010, and the urbanized area associated with the carbon storage loss increased by $0.64 \times 10^{4} \mathrm{~km}^{2}$ (“urbanized area” in the following sections refers to "urbanized area associated with carbon storage loss”). It is worth noting that the size of the newly urbanized area in Beijing-Tianjin-Hebei was close to that in the YRD $\left(0.63 \times 10^{4} \mathrm{~km}^{2}\right)$, however the corresponding carbon storage loss in Beijing-Tianjin-Hebei was 1.51TgC higher than that in the YRD due to the different share structures of cropland, woodland, grassland conversion to new 
urban land across these two regions. In Beijing-Tianjin-Hebei, carbon storage loss caused by conversion from cropland, woodland and grassland was 6.64TgC, 2.82TgC, 1.59TgC, accounting for $55.20 \%, 23.46 \%, 13.21 \%$ of the total, respectively. Though nearly half of carbon storage loss in Beijing-Tianjin-Hebei was caused by the conversion from cropland to urban land, the carbon storage loss caused by conversion from woodland to urban land still made up a relatively high proportion compared with that in the YRD, where the proportion of carbon storage loss caused by conversion from cropland to urban land was $91.72 \%$, and only $7.55 \%$ of carbon storage loss was caused by the conversion from woodland to urban land. Because the composite carbon storage densities of woodland were significantly higher than those of cropland, the relatively large loss of woodland in Beijing-Tianjin-Hebei led to the significantly higher carbon storage loss in comparison with the case of YRD, although the urbanized areas in the two regions had similar size. In the PRD, carbon storage loss caused by the conversion from woodland, cropland, grassland was $3.64 \mathrm{TgC}$, 3.02TgC, $0.29 \mathrm{TgC}$, accounting for 50.08\%, $42.07 \%, 4.00 \%$ of the total, respectively. Both the absolute amount and share of the carbon storage loss caused by the conversion from woodland to urban land were the largest in the PRD. Moreover, though the absolute amount of urbanized area in the PRD over the past 30 years is smaller than that in other two agglomerations, its share in the total land area was the highest (Supporting Information Table S3). If the current trends of land conversion and urbanization continue in the future, the PRD would become the region with the most serious carbon storage loss in the coming decades.

Overall, the urbanized area turned larger from 2000 to 2010, not only within the mega cities, but also expanding to medium size cities of the urban agglomerations (Fig. 2). And more significantly, carbon storage loss of peripheral and semi-peripheral areas intensified, especially in Beijing-Tianjin-Hebei and the PRD. 


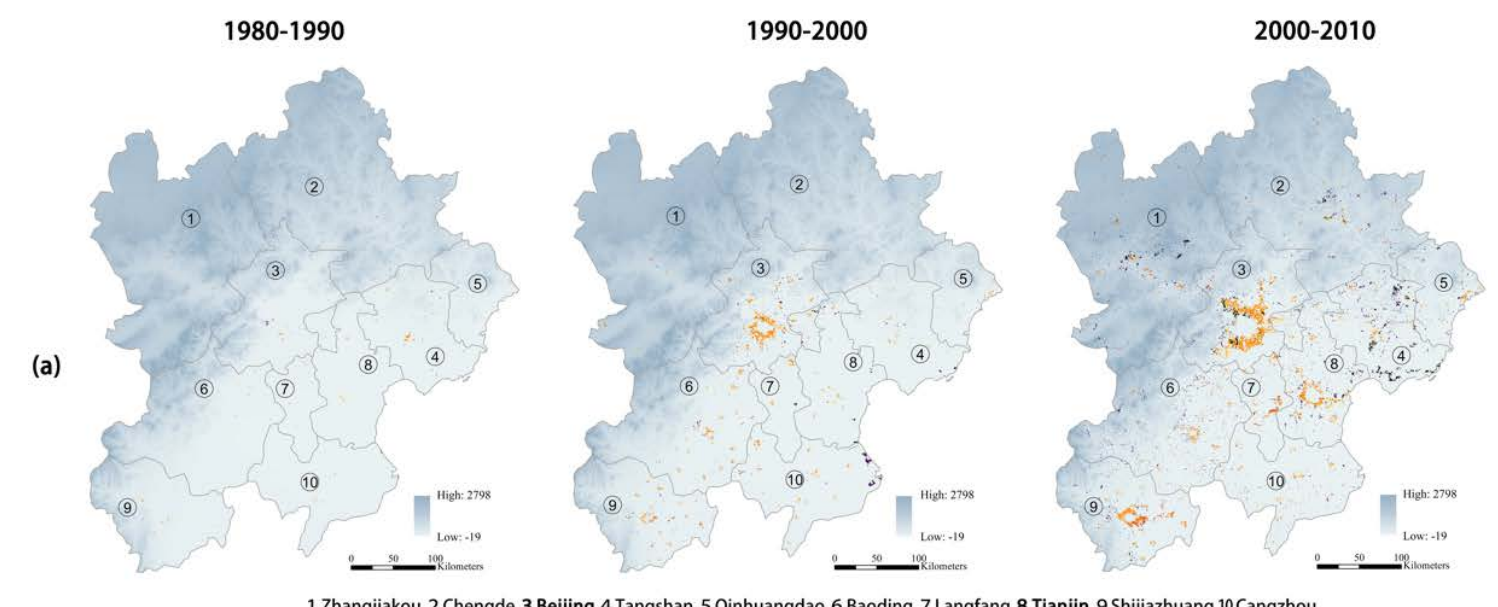

1.Zhangjiakou 2.Chengde 3.Beijing 4.Tangshan 5.Qinhuangdao 6.Baoding 7.Langfang 8.Tianjin 9.Shijiazhuang 10.Cangzhou

(b)
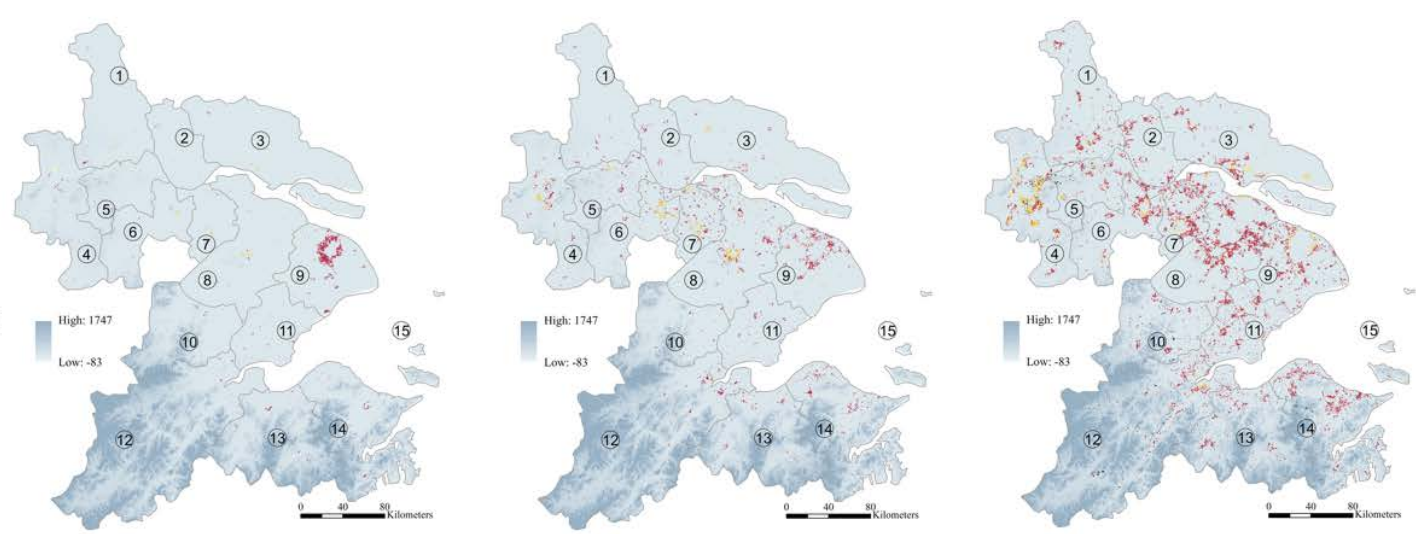

1.Yanghou 2.Taizhou 3.Nantong 4.Nanjing 5.Zhenjiang 6.Changzhou 7.Wuxi 8.Suzhou 9.Shanghai 10.Huzhou 11.Jiaxing 12.Hangzhou 13.Shaoxing 14.Ningbo 15.Zhoushan
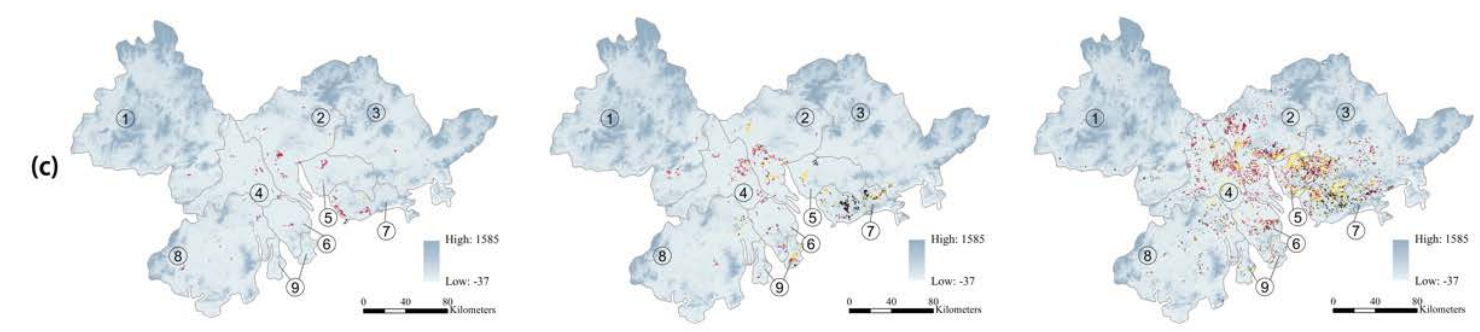

1.Zhaoqing 2.Guangzhou 3.Huizhou 4.Foshan 5.Dongguan 6.Zhongshan 7.Shenzhen 8.Jiangmen 9.Zhuhai

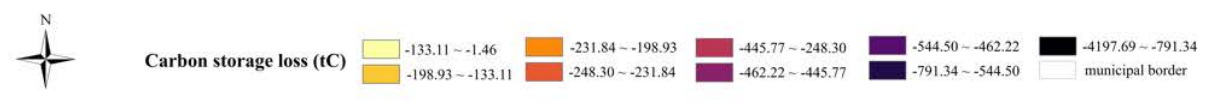

Fig. 2 Carbon storage loss caused by urban expansion in the three urban agglomerations during the period of 1980-2010. a, Beijing-Tianjin-Hebei. b, the Yangtze River Delta (YRD), and c, the Pearl River Delta (PRD). 

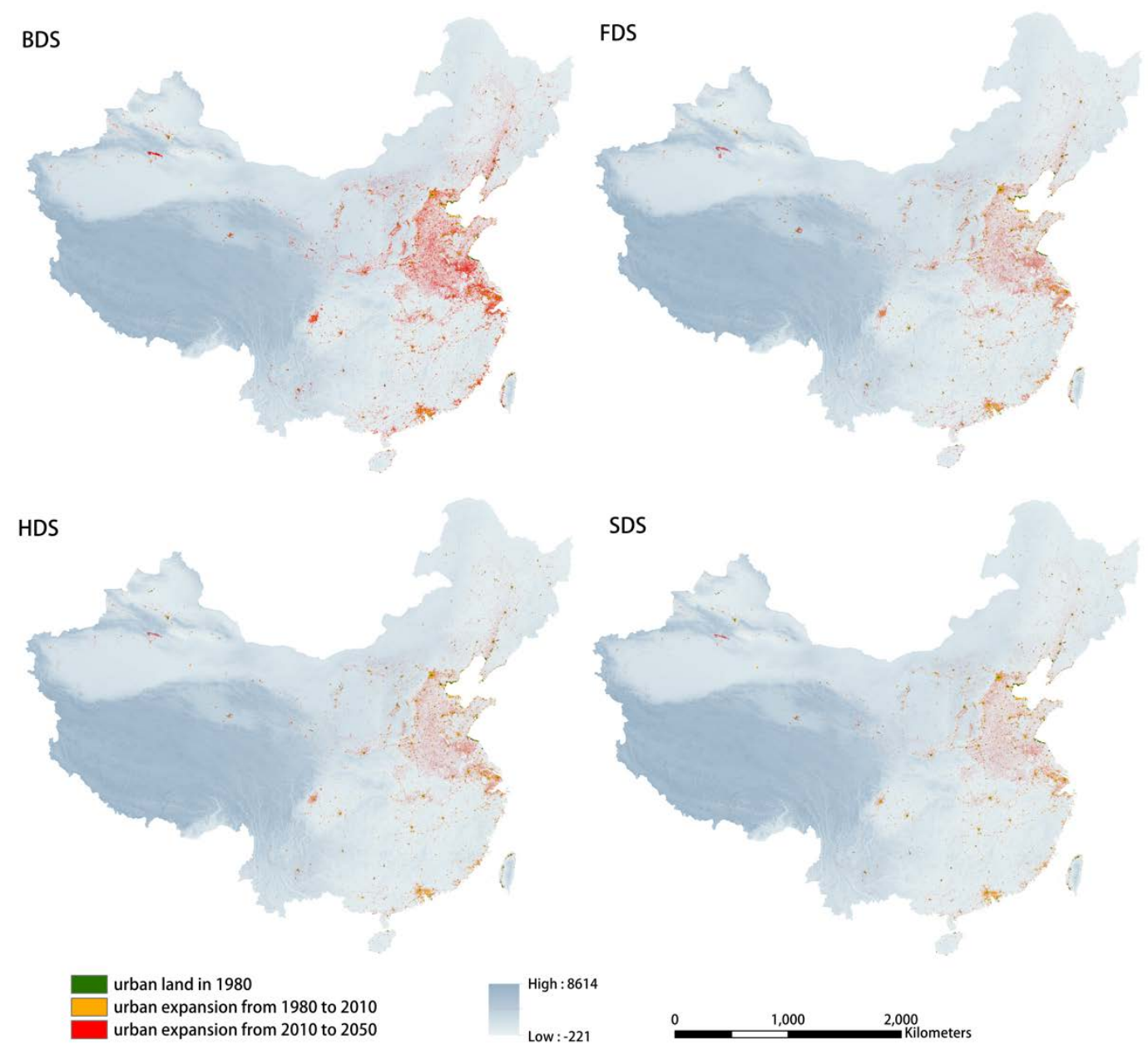

Fig. 3 The urban expansion under four scenarios from 1980 to 2050 in China. BDS stands for the baseline development scenario, FDS for the fast development scenario, HDS for the harmonious development scenario, and SDS for the slow development scenario.

\section{3 | Simulation of carbon storage loss caused by urban expansion from 2010 to 2050}

To test the reliability of the FLUS model in predicting the spatial process of urban expansion in China, 500,000 samples were randomly selected across the Chinese territory, with $70 \%$ of the samples being the training set and the remaining 30\% being the validation set. The demands for the six major land-use types in 2010 were projected using SD module of the FLUS. The projection was based on the land use pattern in 2000 and the driving forces of the socioeconomic factors and environmental tendencies from 2000 to 2010. The spatial evolution of land uses over 2000-2010 was subsequently simulated using the FLUS to meet the demands projected by the 
SD module. The AUC evaluation of the FLUS projection performance shows that the probability-of-occurrence fits well for each of the six land-use types, with the AUC values greater than 0.8 for cropland, grassland and water body, and greater than 0.9 for woodland, urban land and unused land. Therefore, we believed that the FLUS model is applicable for predicting the spatial process of urban expansion in this study. Our simulation results of urban expansion in 2050 are shown in Fig. 3.

Based on the above simulation results of urban expansion, national carbon storage will further decrease during the period of 2010-2050. The predicted annual carbon storage loss will increase to 9.31TgC/y 12.94TgC/y (Supporting Information Table S4), this is more than 2.63 3.66 times the carbon storage loss occurring from 1980 to 2010 (3.54TgC/y). In addition, the proportion of carbon storage loss caused by the three main sources of urbanization will change during the period 2010-2050. During the period 1980-2010, the conversion from cropland to urban land resulted in a decrease of carbon storage by 58.78TgC, which accounted for $55.34 \%$ of the total decrease caused by the urbanization conversion. During the period of 2010-2050, the above share will decrease to 54.26\% and 54.46\% under the FDS and SDS, while increase to 56.22\% and 57.31\% under the BDS and HDS. In addition, the share of carbon storage caused by the conversion from grassland to urban land in the total will decrease by around $4 \%$ under all the four scenarios. The share of carbon storage loss caused by conversion from woodland to urban land in the total will increase by $0.93 \%$ to $4.73 \%$ across the four scenarios.

As the frontrunners of China's urban agglomeration developments, Beijing-Tianjin-Hebei, the YRD and the PRD will continue to experience significant carbon storage loss. Though the three urban agglomerations account for only 3.45\% of the whole country's territory, their share in the national total carbon storage loss caused by the urbanization conversion is predicted to be around 17\% during the period of 2010-2050 (27.98\% during the period of 1980-2010). As shown in Supporting Information Tables S3 and S5, among the three urban agglomerations, the extent of the average annual urbanized area under all four scenarios in Beijing-Tianjin-Hebei will double the corresponding figure in the base period of 1980-2010, and as a consequence, this 
agglomeration will experience the largest carbon storage loss. Carbon storage loss in the YRD is more sensitive to the choices of scenarios, ranging from $0.475 \mathrm{TgC} / \mathrm{y}$ under the SDS to 0.892TgC/y under the FDS. Comparing with the average annual carbon storage loss in the base period of 1980-2010 in the YRD, the corresponding figure under the FDS and SDS will be over 1.5 times and about 0.5 times larger. By contrast, carbon storage loss in the PRD will have a decrement or small increment under all four scenarios in comparison with the loss during the base period of 1980-2010. Interestingly the PRD will be the only region where the average carbon storage loss per unit of urbanized area will increase. Presenting the results by the major land-use type, we can see that the proportion of carbon storage loss caused by the conversion from cropland to urban land in the total loss will decrease in the YRD and PRD under all four scenarios in comparison with the base period of 1980-2010, whereas Beijing-Tianjin-Hebei will move to the opposite direction. The proportion of carbon storage loss caused by the conversion from woodland to urban land in the total will decrease in Beijing-Tianjin-Hebei under all four scenarios in comparison with the case during the base period of 1980-2010, whereas the YRD and PRD will experience an increase (Supporting Information Table S6). It is worth highlighting that in the PRD, carbon storage loss due to the conversion from woodland to urban land will accounts for over $50 \%$ of the total loss under all four scenarios.

Figs. 4 and 5 present the spatial distributions of carbon storage loss over the base period of 1980-2010 and the four scenarios for 2010-2050. As shown in the maps, the carbon storage loss is more serious under BDS and FDS in all three agglomerations. In Beijing-Tianjin-Hebei, the carbon storage loss in already urbanized part of Beijing will no longer take place. However, high carbon storage loss will scatter in the western Beijing, southern Tangshan and the central part of Chengde under all four scenarios. Across the whole region of the YRD, the urbanized area in virtually all cities will continue to expand and this will lead to high carbon storage loss across most of cities in the region. Notably, the spatial discrepancy of carbon storage loss is the most obvious in the YRD in comparison with other two regions. Under all the scenarios, Nanjing, Hangzhou and Shaoxing will experience high carbon storage loss. Wuxi and Suzhou will join the 
same high-loss rank under BDS and FDS. The PRD will experience serious carbon storage loss as well. High carbon storage loss will occur in each city of the PRD under all the scenarios. Furthermore, high carbon storage loss in Guangzhou, Shenzhen and Zhuhai will be widespread under BDS and FDS. 

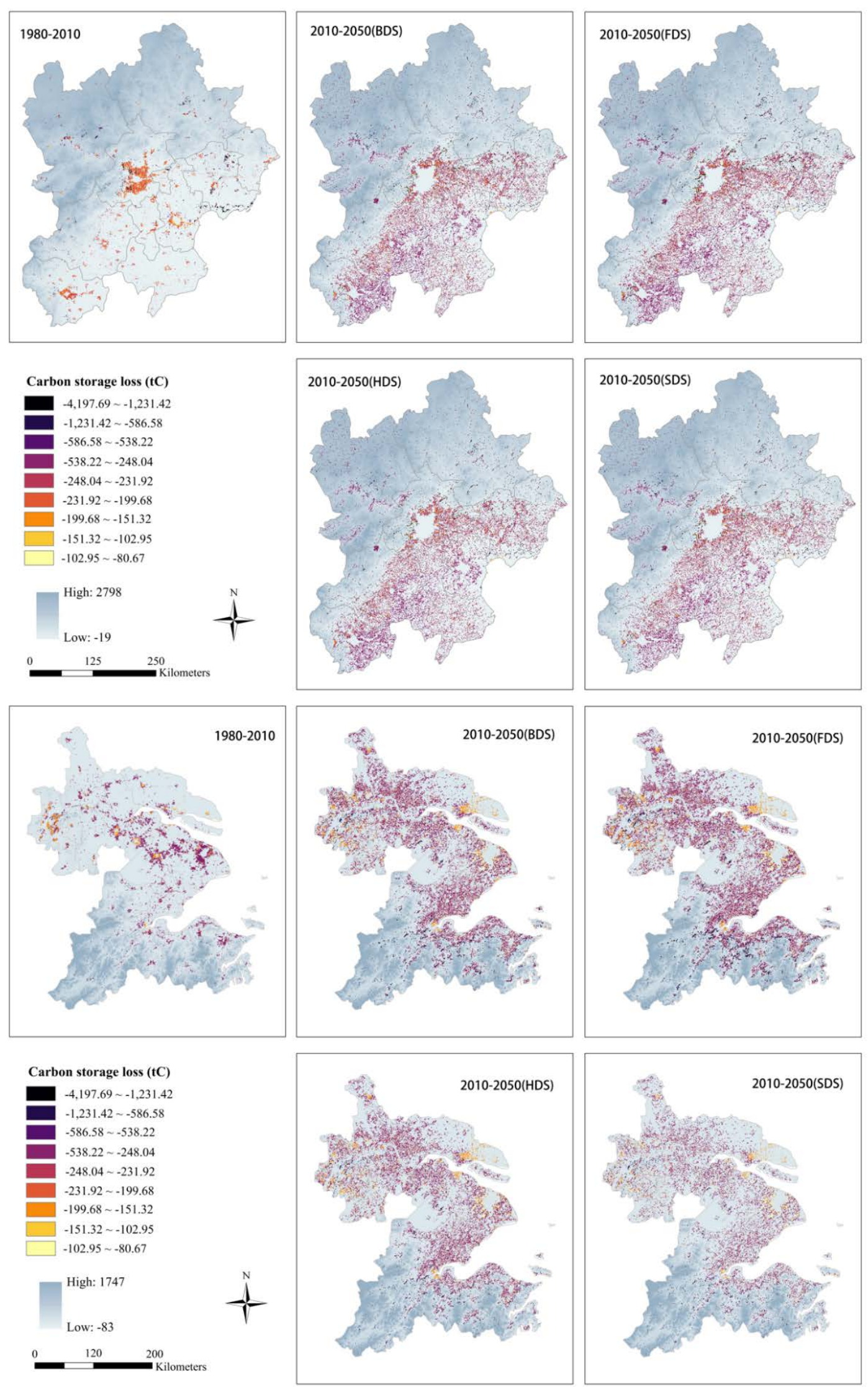
Fig. 4 Carbon storage loss caused by urban expansion in Beijing-Tianjin-Hebei (5 maps in the upper panel) and the YRD (5 maps in the lower panel) during the periods of 1980-2010 and under the four scenarios for 2010-2050.
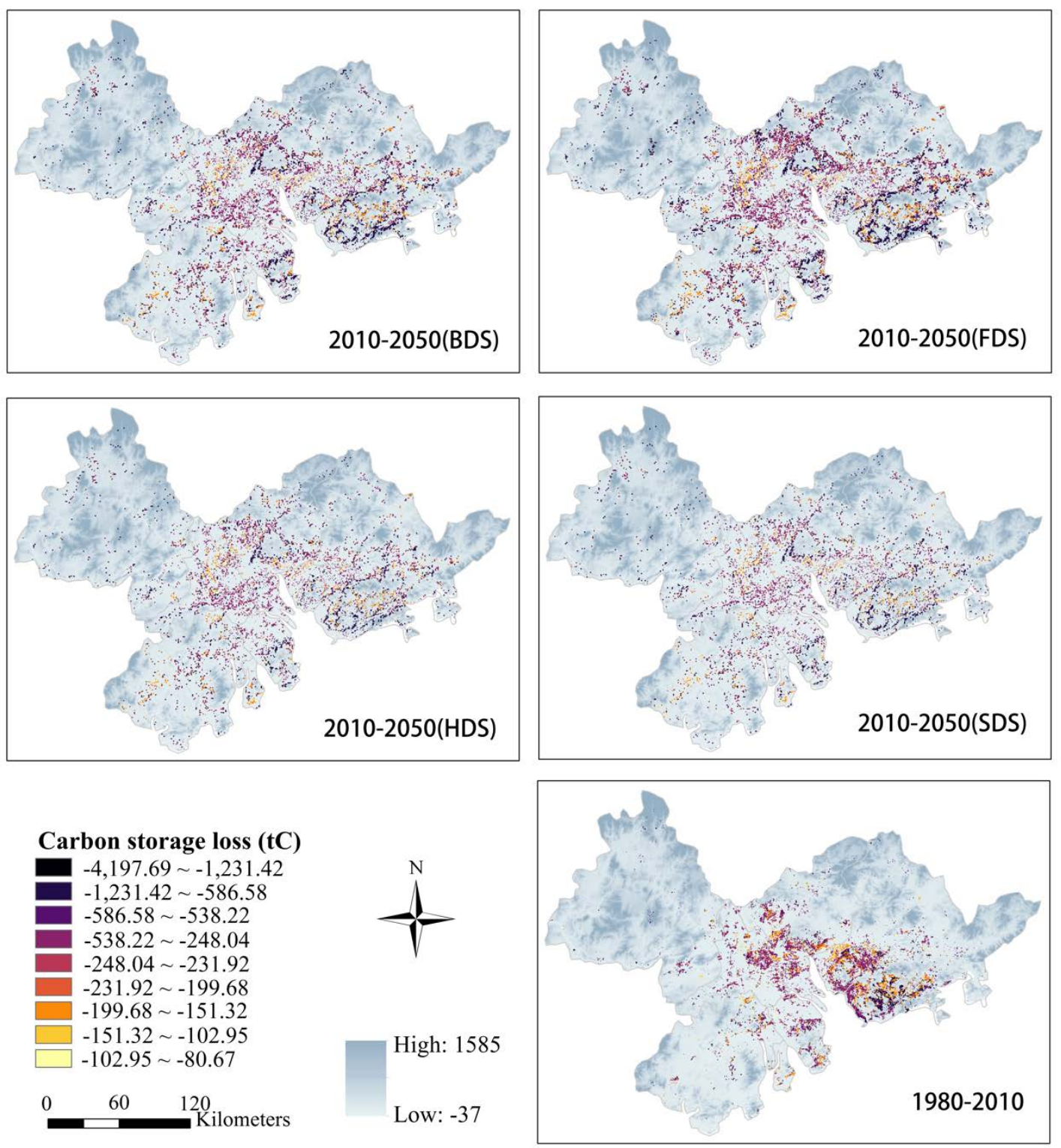

Fig. 5 Carbon storage loss caused by urban expansion in the PRD during the periods of 1980-2010 and under the four scenarios for 2010-2050. 


\section{4 | Limitations and implications}

In this study, we coupled the FLUS model and the InVEST model to simulate the impacts of urban expansion on terrestrial carbon storage. The InVEST model is globally popular for its simplicity, stability, predictability, and ease of application across a large number of polygons with less intensive input requirement. However, its ease application is associated with limitations. The InVEST model assumes that all land-use types are at a fixed storage level, meaning that the only change in carbon storage over time is due to the change of land-use types. To reduce the biasness caused by this limitation requires a more detailed classification system that explicitly considers natural carbon sequestration and attaches years to land-use types, and applies the secondary classification of the climatic zone to subdivide geographical regions.

The uncertainty analysis of our study focused on the large variations across different socioeconomic development scenarios as presented in the Shared Socioeconomic Development Pathway of the IPCC and climate change scenarios as implied in the Representative Concentration Pathways of the IPCC. While this uncertainty analysis is in line with the large body of literature on the implementation of the SSPs, ${ }^{44,45}$ the limitation of such analysis is that it ignores uncertainties associated with the plausible variations in key input parameters which can propagate through the CA modelling processes. Such limitation can be addressed by more computer intensive Monte Carlo simulations.

The FLUS model is conducted under four scenarios of SSP-RCP combinations. While these scenarios are more in line with the ongoing policies urbanization promotion and farmland protection. More ecologically friendly urbanization policies are needed to reduce the significant carbon storage losses associated with the simulated urbanization paths. Such policies should include the introduction of green roofs, green walls, and permeable pavement; restoration of ecological bodies; and forest protection at the edge of the city. 


\section{- AUTHOR INFORMATION}

\section{Corresponding Authors}

*E-mail: wangshj8@mail.sysy.edu.cn. Tel.: +86-02084111963. Fax: +86-020841111963 (S.W.).

*E-mail: lsun123@umd.edu. Tel.: (301) 405-8131. Fax: (301) 405-8131 (L.S.).

\section{Notes}

The authors declare no competing financial interest.

\section{Acknowledgments}

This work was supported by the National Natural Science Foundation of China (41601151), Guangdong Special Support Program (2016A030310149) and Pearl River S\&T Nova Program of Guangzhou (201806010187), China Scholarship Council (201806385014).

\section{Supporting Information}

Tables S1-S6 on land use types, carbon density parameters, and additional results.

Figures S1-S5 on flowchart of the modeling procedures, and maps of background information and additional results

\section{REFERENCES}

1. Prentice, I.C., Farquhar, G.D., Fasham, M.J.R., Goulden, M.L., Heimann, M., Jaramillo, V.J., Kheshgi, H.S., Le Quéré, C., Scholes, R.J., Wallace, D.W.R., Archer, D., Ashmore, M.R., Aumont, O., Baker, D., Battle, M., Bender, M., Bopp, L.P., Bousquet, P., Caldeira, K., Ciais, P., Cox, P.M., Cramer, W., Dentener, F., Enting, I.G., Field, C.B., Friedlingstein, P., Holland, E.A., Houghton, R.A., House, J.I., Ishida, A., Jain, A.K., Janssens, I.A., Joos, F., Kaminski, T., Keeling, C.D., Keeling, R.F., Kicklighter, D.W., Kohfeld, K.E., Knorr, W., Law, R., Lenton, T., Lindsay, K., Maier-Reimer, E., Manning, A.C., Matear, R.J., McGuire, A.D., Melillo, J.M., Meyer, R., Mund, M., Orr, J.C., Piper, S., Plattner, K., Rayner, P.J., 
Sitch, S., Slater, R., Taguchi, S., Tans, P.P., Tian, H.Q., Weirig, M.F., Whorf, T., Yool, A., Pitelka, L., Ramirez Rojas, A. (2001) The carbon cycle and atmospheric carbon dioxide. Cambridge University Press.

2. Ni, J. Carbon storage in Chinese terrestrial ecosystems: approaching a more accurate estimate. Climatic Change, 2013, 119, 905-917.

3. Atwood, T.B., Connolly, R.M., Almahasheer, H., Carnell, P.E., Duarte, C.M., Ewers Lewis, C.J., Irigoien, X., Kelleway, J.J., Lavery, P.S., Macreadie, P.I., Serrano, O., Sanders, C.J., Santos, I., Steven, A.D.L., Lovelock, C.E. Global patterns in mangrove soil carbon stocks and losses. Nature Climate Change, 2017, 7, 523-528.

4. Garnett, M.H., Ineson, P., Stevenson, A.C., Howard, D.C. Terrestrial organic carbon storage in a British moorland. Global Change Biology, 2001, 7, 375-388.

5. Prentice, I.C., Farquhar, G.D., Fasham, M.J.R., Goulden, M.L., Heimann, M., Jaramillo, V.J., Kheshgi, H.S., Le Quéré, C., Scholes, R.J., Wallace, D.W.R., Archer, D., Ashmore, M.R., Aumont, O., Baker, D., Battle, M., Bender, M., Bopp, L.P., Bousquet, P., Caldeira, K., Ciais, P., Cox, P.M., Cramer, W., Dentener, F., Enting, I.G., Field, C.B., Friedlingstein, P., Holland, E.A., Houghton, R.A., House, J..I, Ishida, A., Jain, A.K., Janssens, I.A., Joos, F., Kaminski, T., Keeling, C.D., Keeling, R.F., Kicklighter, D.W., Kohfeld, K.E., Knorr, W., Law, R., Lenton, T., Lindsay, K., Maier-Reimer, E., Manning, A.C., Matear, R.J., McGuire, A.D., Melillo, J.M., Meyer, R., Mund, M., Orr, J.C., Piper, S., Plattner, K., Rayner, P.J., Sitch, S., Slater, R., Taguchi, S., Tans, P.., Tian, H.Q., Weirig, M.F., Whorf, T., Yool, A., Pitelka, L., Ramirez, R.A. (2001) The Carbon Cycle and Atmospheric Carbon Dioxide. In: Climate Change 2001: the Scientific Basis. Contributions of Working Group I to the Third Assessment Report of the Intergovernmental Panel on Climate Change. ed. by Houghton, J.T., Ding, Y., Griggs, D.J., Noguer, M., van der Linden, P.J., Dai, X., Maskell, K. and Johnson, C.A. Cambridge University Press, Cambridge, UK, pp. 185-237.

6. Schröter, D., Crame,r W., Leemans, R., Prentice, I.C., Araújo, M.B., Arnell, N.W., Bondeau, A., Bugmann, H., Carter, T.R., Gracia, C.A., de la Vega-Leinert, A.C., Erhard, M., Ewert, F., 
Glendining, M., House, J.I., Kankaanpää, S., Klein, R.J.T., Lavorel, S., Lindner, M., Metzger, M.J., Meyer, J., Mitchell, T.D., Reginster, I., Rounsevell, M., Sabaté, S., Sitch, S., Smith, B., Smith, J., Smith, P., Sykes, M.T., Thonicke, K., Thuiller, W., Tuck, G., Zaehle, S., Zierl, B. Ecosystem Service Supply and Vulnerability to Global Change in Europe. Science, 2005, 310, 1333-1337.

7. Nelson, E., Sander, H., Hawthorne, P., Conte, M., Ennaanay, D., Wolny, S., Manson, S., Polasky, S. Projecting Global Land-Use Change and Its Effect on Ecosystem Service Provision and Biodiversity with Simple Models. PloS one, 2010, 5, e14327.

8. Swetnam, R.D., Fisher, B., Mbilinyi, B.P., Munishi, P.K., Willcock, S., Ricketts, T., Mwakalila, S., Balmford, A., Burgess, N.D., Marshall, A.R., Lewis, S.L. Mapping socio-economic scenarios of land cover change: A GIS method to enable ecosystem service modelling. Journal of Environmental Management, 2011, 92, 563-574.

9. He, C., Zhang, D., Huang, Q., Zhao, Y. Assessing the potential impacts of urban expansion on regional carbon storage by linking the LUSD-urban and InVEST models. Environmental Modelling \& Software, 2016, 75, 44-58.

10. Binford, M.W., Gholz, H.L., Starr, G., Martin, T.A. Regional carbon dynamics in the southeastern U.S. coastal plain: Balancing land cover type, timber harvesting, fire, and environmental variation. Journal of Geophysical Research: Atmospheres, 2006, 111, 317.

11. Schulp, C.J.E,, Nabuurs, G..J, Verburg, P.H. Future carbon sequestration in Europe-Effects of land use change. Agriculture, 2008, 127, 251-264.

12. Zhu, Z., Bouchard, M., Butman, D., Hawbaker, T., Li, Z., Liu, J., Liu S, McDonald C, Reker R, Sayler K, Sleeter B, Sohl T, Stackpoole S, Wein A. Baseline and projected future carbon storage and greenhouse-gas fluxes in the Great Plains region of the United States. U.S. Geological Survey, Reston, Virginia: 2011.

13. Chuai, X., Huang, X., Lai, L., Wang, W., Peng, J., Zhao, R. Land use structure optimization based on carbon storage in several regional terrestrial ecosystems across China. Environmental Science \& Policy, 2013, 25, 50-61. 
14. Zhang, M., Huang, X., Chuai, X., Yang, H., Lai, L., Tan, J. Impact of land use type conversion on carbon storage in terrestrial ecosystems of China: A spatial-temporal perspective. Scientific Reports, 2015, 5, 5667.

15. Houghton, R., Hackler, J., Lawrence, K. The U.S. Carbon budget: contributions from land-use change. Science, 1999, 285, 574-578.

16. DeFries, R.S., Houghton, R.A., Hansen, M.C., Field, C.B., Skole, D., Townshend, J. Carbon emissions from tropical deforestation and regrowth based on satellite observations for the 1980s and 1990s. Proceedings of the National Academy of Sciences of the United States of America, 2002, 99, 14256-14261.

17. Houghton, R. Magnitude, distribution and causes of terrestrial carbon sinks and some implications for policy. Climate Policy, 2002, 2, 71-88.

18. Leite, C.C., Costa, M.H., Soares-Filho, B.S., Hissa L.D.V. Historical land use change and associated carbon emissions in Brazil from 1940 to 1995. Global Biogeochemical Cycles, 2012, 26, GB2011.

19. UN (2008) World urbanization prospects: The 2007 revision. New York UN.

20. Mcdonald, R.I., Kareiva, P., Forman, R.T.T. The implications of current and future urbanization for global protected areas and biodiversity conservation. Biological conservation, 2008, 141, 1695-1703.

21. Davies, Z.G., Edmondson, J.L., Heinemeyer, A., Leake, J.R., Gaston, K.J. Mapping an urban ecosystem service: quantifying above-ground carbon storage at a city-wide scale. Journal of Applied Ecology, 2011, 48, 1125-1134.

22. Zhao, S., Liu, S., Sohl, T., Young, C., Werner, J. Land use and carbon dynamics in the southeastern United States from 1992 to 2050. Environmental Research Letters, 2013, 8, 044022.

23. Areas, E. Ecosystem appropriation by cities. Ambio, 1997, 26, 167-172. 
24. Imhoff, M. Using nighttime DMSP/OLS images of city lights to estimate the impact of urban land use on soil resources in the United States. Remote Sensing of Environment, 1997, 59, 105-117.

25. Schimel, D. Contribution of Increasing $\mathrm{CO}_{2}$ and Climate to Carbon Storage by Ecosystems in the United States. Science, 2000, 287, 2004-2006.

26. Yu, D.Y., Pan, Y.Z., Liu, X., Wang, Y.Y., Zhu, W.Q. Ecological capital measurement by remotely sensed data for Huahou and its socio-economic application. Chinese Journal of Plant Ecology, 2006,30, 404-413.

27. Yeh, A.O., Li, X. Measurement and monitoring of urban sprawl in a rapidly growing region using entropy. Photogrammetric Engineering \& Remote Sensing, 2001, 67, 83-90.

28. Wang, H., He, Q., Liu, X., Zhuang, Y., Hong, S. Global urbanization research from 1991 to 2009: A systematic research review. Landscape and Urban planning, 2012, 104, 299-309.

29. Song, W., Deng, X., Yuan, Y., Wang, Z., Li, Z. Impacts of land-use change on valued ecosystem service in rapidly urbanized North China Plain. Ecological Modelling, 2015, 318, 245-253.

30. Guan, D., Klasen, S., Hubacek, K., Feng, K.S., Liu, Z., He, K.B., Geng, Y., Zhang, Q. Determinants of stagnating carbon intensity in China. Nature Climate Change, 2014, 4, 1017-1023.

31. United Nations, 2015, Paris Agreement. Available at http://unfccc.int/files/essential_background/convention/application/pdf/english_paris_agree ment.pdf

32. Liang, S. Research on the Urban Influence Domains in China. International Journal of Geographical Information Science, 2009, 23, 1527-1539.

33. He, C., Zhao, Y., Tian, J., Shi, P. Modeling the urban landscape dynamics in a megalopolitan cluster area by incorporating a gravitational field model with cellular automata. Landscape and Urban planning, 2013, 113, 78-89. 
34. Liu, X., Derudder, B., Taylor, P. Mapping the evolution of hierarchical and regional tendencies in the world city network, 2000-2010. Computers, Environment and Urban Systems, 2014, 43, 51-66.

35. Wang, Z., Hoffmann, T., Six, J., Kaplan, J.O., Govers, G., Doetterl, S., Van, O.K. Human-induced erosion has offset one-third of carbon emissions from land cover change. Nature Climate Change, 2017, 7, 345-349.

36. Liu, X., Liang, X., Li, X., Xu, X., Ou, J., Chen, Y., Li, S., Wang, S., Pei, S. A future land use simulation model (FLUS) for simulating multiple land use scenarios by coupling human and natural effects. Landscape and Urban Planning, 2017, 168, 94-116.

37. Batty, M., Xie, Y., Sun, Z. Modeling urban dynamics through GIS-based cellular automata. Computers, Environment and Urban Systems, 1999, 23, 205-233.

38. Li, X., Liu, X., Gong, P. Integrating ensemble-urban cellular automata model with an uncertainty map to improve the performance of a single model. International Journal of Geographical Information Science, 2015, 29, 762-785.

39. Li, X., Chen, Y., Liu, X., Xu, X., Chen, G. Experiences and issues of using cellular automata for assisting urban and regional planning in China. International Journal of Geographical Information Science, 2017, 68, 1-24.

40. Pontius, R.G., Boersma, W., Castella, J.C., Clarke, K. Comparing the input, output, and validation maps for several models of land change. The Annals of Regional Science, 2008, 42, 11-37.

41. Li, X., Chen, G., Liu, X., Liang, X., Wang, S.J., Chen, Y.M., Pei, F.S., Xu, X.C. A New Global Land-Use and Land-Cover Change Product at a 1-km Resolution for 2010 to 2100 Based on Human-Environment Interactions. Annals of the American Association of Geographers, 2017, 107, 1040-1059.

42. Li, X., Yeh. A.G. Neural-network-based cellular automata for simulating multiple land use changes using GIS. International Journal of Geographical Information Science, 2002, 16, 323-343. 
43. Sohl, T.L., Sleeter, B.M., Sayler, K.L., Sayle,r K.L., Bouchard, M.A., Reker, R.R., Bennett, S.L., Sleeter, R.R., Kanengieter, R.L., Zhu, Z.L. Spatially explicit land-use and land-cover scenarios for the Great Plains of the United States. Agriculture, 2012, 153, 1-15.

44. O’Neill, B. C., Tebaldi, C. van Vuuren, D. P., Eyring, V., Friedlingstein, P., Hurtt, G., Knutti, R., Kriegler, E., Lamarque, J.-F., Lowe, J., Meehl, G. A., Moss, R., Riahi, K., Sanderson, B. M. The Scenario Model Intercomparison Project (ScenarioMIP) for CMIP6. Geosci. Model Dev., 2016, 9, 3461-3482.

45. Riahi, K., van Vuuren, D.P., Kriegler, E., Edmonds, J., C. O’Neill, B.C., Fujimori, S., Bauer, N., Calvin, K., Dellink, R., Fricko, O., Lutz, W., Popp, A., Cuaresma, J.C., Samir, K.C,, Leimbach, M., Jiang, L., Kram, T., Rao, S., Emmerling, J., Ebi, K., Hasegawa, T., Havlik, P., Humpenöder, F., Da Silva, L.A., Smith, S., Stehfest, E., Bosetti, V., Eom, J., Gernaat, D., Masui, T., Rogelj, J., Strefler, J., Drouet, L., Krey, V., Luderer, G., Harmsen, M., Takahashi, K., Baumstark, L., Doelman, J.C., Kainuma, M., Klimont, Z., Marangoni, G., Lotze-Campen, H., Obersteiner, M., Tabeau, A., Tavon, M. The Shared Socioeconomic Pathways and their energy, land use, and greenhouse gas emissions implications: An overview. Global Environmental Change, 2017, 42, 153-168.

46. Chen, Y., Li, X., Liu, X., Bin, A. Modeling urban land-use dynamics in a fast developing city using the modified logistic cellular automaton with a patch-based simulation strategy. International Journal of Geographical Information Science, 2013, 28, 234-255.

47. Hanley, J. A., McNeil, B. J. The meaning and use of the area under a receiver operating characteristic (ROC) curve. Radiology, 1982, 143, 29-36.

48. Fan, J., Zhong, H., Harris, W., Yu, G., Wang, S., Hu, Z., Yue, Y. Carbon storage in the grasslands of China based on field measurements of above- and below-ground biomass. Climatic Change, 2007, 86, 375-396.

49. Jaiarree, S.; Chidthaisong, A.; Tangtham, N.; Polprasert C.; Sarobol E.; Tyler S.C. Soil Organic Carbon Loss and Turnover Resulting from Forest Conversion to Maize Fields in Eastern Thailand. Pedosphere, 2011, 21, 581-590. 
50. Pan, Y., Luo, T., Birdsey, R., Hom, J., Melillo, J. New Estimates of Carbon Storage and Sequestration in China's Forests: Effects of Age-Class and Method On Inventory-Based Carbon Estimation. Climatic Change, 2004, 67, 211-236.

51. Piao, S.; Fang, J.Y.; Zhu B.; Tan, K. Forest biomass carbon stocks in China over the past 2 decades: Estimation based on integrated inventory and satellite data. Journal of Geophysical Research, 2005, 110, G01006.

52. Delphin, S.; Escobedo, F.J.; Abd-Elrahman, A.; Cropper, W.P. Urbanization as a land use change driver of forest ecosystem services. Land Use Policy, 2016, 54, 188-199.

53. Nowak, D.J.; Crane, D.E. Carbon storage and sequestration by urban trees in the USA. Environmental pollution, 2002, 116, 381-389.

54. Churkina, G. (2012) Carbon Cycle of Urban Ecosystems. In: Carbon Sequestration in Urban Ecosystems, pp. 315-330. Springer Netherlands, Dordrecht.

55. Guo, L.B.; Gifford, R.M. Soil carbon stocks and land use change: a meta analysis. Global Change Biology, 2002, 8, 345-360.

56. Hou, X. Vegetation atlas of China. Chinese academy of Science, the editorial Board of Vegetation map of China, 2001.

57. Song, G.; Li, L.; Pan, G.; Zhang, Q. Topsoil organic carbon storage of China and its loss by cultivation. Biogeochemistry, 2005, 74, 47-62.

58. Pan, G.; Smith, P.; Pan, W. The role of soil organic matter in maintaining the productivity and yield stability of cereals in China. Agriculture, 2009, 129, 344-348. 